OPEN ACCESS

Edited by: Darius Widera

University of Reading, United Kingdom

Reviewed by:

Maria A. Mariggiò,

University of Studies G. d'Annunzio

Chieti and Pescara, Italy

Amar M. Singh

University of Georgia, United States

*Correspondence:

Philipp Capetian

Capetian_P@ukw.de

${ }^{\dagger}$ These authors have contributed equally to this work

Specialty section:

This article was submitted to

Stem Cell Research

a section of the journal

Frontiers in Cell and Developmental

Biology

Received: 28 May 2021

Accepted: 30 July 2021

Published: 18 August 2021

Citation

Krajka V, Naujock M, Pauly MG, Stengel F, Meier B, Stanslowsky N,

Klein C, Seibler P, Wegner F and

Capetian P (2021) Ventral Telencephalic Patterning Protocols for Induced Pluripotent Stem Cells.

Front. Cell Dev. Biol. 9:716249.

doi: 10.3389/fcell.2021.716249

\section{Ventral Telencephalic Patterning Protocols for Induced Pluripotent Stem Cells}

\author{
Victor Krajka', Maximilian Naujock ${ }^{2}$, Martje G. Pauly ${ }^{1}$, Felix Stengel ${ }^{1}$, Britta Meier ${ }^{1}$, \\ Nancy Stanslowsky ${ }^{2}$, Christine Klein ${ }^{1}$, Philip Seibler ${ }^{1}$, Florian Wegner ${ }^{2+}$ and \\ Philipp Capetian ${ }^{1,3 *+}$
}

\begin{abstract}
${ }^{1}$ Institute of Neurogenetics, University of Lübeck, Lübeck, Germany, ${ }^{2}$ Department of Neurology, Hannover Medical School, Hanover, Germany, ${ }^{3}$ Department of Neurology, University Hospital Würzburg, Würzburg, Germany
\end{abstract}

The differentiation of human induced pluripotent stem cells (hiPSCs) into specific cell types for disease modeling and restorative therapies is a key research agenda and offers the possibility to obtain patient-specific cells of interest for a wide range of diseases. Basal forebrain cholinergic neurons (BFCNs) play a particular role in the pathophysiology of Alzheimer's dementia and isolated dystonias. In this work, various directed differentiation protocols based on monolayer neural induction were tested for their effectiveness in promoting a ventral telencephalic phenotype and generating BFCN. Ventralizing factors [i.e., purmorphamine and Sonic hedgehog $(\mathrm{SHH})$ ] were applied at different time points, time intervals, and concentrations. In addition, caudal identity was prevented by the use of a small molecule XAV-939 that inhibits the Wntpathway. After patterning, gene expression profiles were analyzed by quantitative PCR (qPCR). Rostro-ventral patterning is most effective when initiated simultaneously with neural induction. The most promising combination of patterning factors was $0.5 \mu \mathrm{M}$ of purmorphamine and $1 \mu \mathrm{M}$ of XAV-939, which induces the highest expression of transcription factors specific for the medial ganglionic eminence, the source of GABAergic inter- and cholinergic neurons in the telencephalon. Upon maturation of cells, the immune phenotype, as well as electrophysiological properties were investigated showing the presence of marker proteins specific for BFCN (choline acetyltransferase, ISL1, p75, and NKX2.1) and GABAergic neurons. Moreover, a considerable fraction of measured cells displayed mature electrophysiological properties. Synaptic boutons containing the vesicular acetylcholine transporter (VACHT) could be observed in the vicinity of the cells. This work will help to generate basal forebrain interneurons from hiPSCs, providing a promising platform for modeling neurological diseases, such as Alzheimer's disease or Dystonia.

Keywords: induced pluripotent stem cells, medial ganglionic eminence, Sonic hedgehog, XAV-939, purmorphamine, basal forebrain cholinergic neurons, GABAergic neurons, electrophysiology

\section{INTRODUCTION}

To gain a profound understanding of diseases at the molecular level, cell models are employed for research. However, the particular use of species-specific primary human cells is severely limited by either ethical concerns, e.g., embryonic stem cell-derived samples, or the poor accessibility and low cell yield of human tissue specimens from brain surgeries (Sterneckert et al., 2014). These 
issues can be circumvented by using human induced pluripotent stem cells (hiPSCs), which can be differentiated into all three germ layers. For this approach, somatic cells are obtained from patients and reprogrammed into hiPSCs by the induced expression of four transcription factors (OCT4, SOX2, KLF4, and c-MYC) (Takahashi et al., 2007). The next relevant step is the development of reliable directed differentiation protocols to generate the desired cells in sufficient quantity, physiological functionality, and maturity.

To model neurological diseases causing, e.g., dementia or movement disorders, the corresponding affected neural cell types can be generated using the hiPSC technology. For this purpose, hiPSCs are differentiated into neural progenitor cells (NPCs) by inducing a neuroectodermal cell fate (Chambers et al., 2009). Further differentiation of neural stem cells, without the addition of morphogens, reveals cell populations resembling the cerebral cortex (Gaspard et al., 2008). Therefore, neural differentiation into a dorsal telencephalic identity is denoted as an intrinsic "default" pathway (van den Ameele et al., 2014). To obtain specified regional identities along the rostro-caudal and dorsoventral neural axis (Figure 1A), signaling peptides (so-called morphogens) or their small-molecule counterparts need to be administered (Petros et al., 2011). By their addition, NPCs can be patterned into desired neuronal lineages, by mimicking the neurogenesis of specific brain regions, resulting in dopaminergic, glutamatergic, and GABAergic neurons (Wang et al., 2015; Sun et al., 2016; Cao et al., 2017). For our study, we focused on the most ventral part of the telencephalon - the medial ganglionic eminence (MGE) (Figure 1B) - from which basal forebrain cholinergic neurons (BFCNs) and GABAergic interneurons arise (Sussel et al., 1999). Alterations in these cell types are associated with sporadic Alzheimer's disease (Whitehouse et al., 1982; Coyle et al., 1983) and isolated dystonia (Levy and Hallett, 2002).

To recapitulate the neurogenesis of the MGE in vitro, activation of the Sonic hedgehog $(\mathrm{SHH})$ pathway is required, which has a strong ventralizing impact during neural tube development (Briscoe et al., 1999; Figure 1). In vivo as well as in vitro, this leads to an upregulation of the Homeobox Protein Nkx-2.1, a key regulator for the MGE development (Ericson et al., 1996; Sussel et al., 1999; Harfe et al., 2004; Gulacsi and Anderson, 2006; Liu et al., 2013b). Alternatively, the Wnt signaling pathway can be inhibited, limiting a dorso-caudal regionalization (Backman et al., 2005). However, MGE-like cells can be generated either by solely activating the $\mathrm{SHH}$ pathway (Li et al., 2009; Liu et al., 2013b) or by modulating the SHHand Wnt-pathway (Li et al., 2009; Liu et al., 2013b; Maroof et al., 2013), respectively. This combined approach seems to be more efficient.

For rostro-ventralization, the recombinant proteins SHH/DKK1 (Dickkopf-related protein 1; Wnt antagonist) can be applied (Li et al., 2009). SHH can be substituted by the small molecule purmorphamine (Smoothened activator), DKK1 by XAV-939 (tankyrase inhibitor) (Sinha and Chen, 2006; Huang et al., 2009; Liu et al., 2013a; Maroof et al., 2013; Nicholas et al., 2013). In contrast to the recombinant proteins, the latter small molecules are more cost-effective and have longer half-lives in cell culture. The concentration, timing, and duration of purmorphamine/SHH administration have a critical impact on which neuronal cell types accumulate in the in vitro population. These range from hypothalamic and striatal projection neurons to cortical and striatal interneurons (van den Ameele et al., 2014).

Here, we aimed to establish a protocol for the efficient generation of BFCNs and GABAergic interneurons. For this, we compared the efficiency of recombinant $\mathrm{SHH}$ with the small molecule purmorphamine, the most potent morphogen concentration for the upregulation of MGE-specific marker genes, and the most effective ventralization time interval. Finally, we investigated whether the neuronal cells retained their regional identity after final maturation, which resembled cholinergic neurons, and assessed their neurophysiological characteristics.

\section{RESULTS}

\section{Differentiation of Ventral Telencephalic Cell Populations From hiPSC}

Our adherent ventral telencephalic patterning protocol was based on previous studies (Chambers et al., 2009; Li et al., 2009; Seibler et al., 2011; Ma et al., 2012; Liu et al., 2013a; Maroof et al., 2013; Nicoleau et al., 2013), and began with the 2D cultivation of a dense uniform hiPSC monolayer (Figure 2A). Neural induction was initiated by dual SMAD inhibition via the administration of SB-431542 and LDN-193189, inhibiting the transforming growth factor-beta (TGF- $\beta$ ), activin/nodal, and bone morphogenetic protein (BMP) signaling (Figure 2D; Chambers et al., 2009; Qi et al., 2017). Also, morphogens were added to the medium to achieve a rostro-ventral patterning [for rostralization the small molecule XAV-939 (XAV); for ventralization either purmorphamine $(\mathrm{Pu})$ or the recombinant protein $\mathrm{SHH}$ ] (Figure 2D). During this stage, the morphology of the cellular monolayer acquired in some parts an inner structure resembling neural rosettes (Figure 2B), which are considered to be the in vitro analog of the neural tube in neurogenesis (Fedorova et al., 2019). At the last stage of the protocol, the cells matured and neuronal cells with long neurites emerged (Figure 2C).

Our main focus of this study was to optimize the ventralization efficiency during rostro-ventral pattering. For this purpose, the patterning potency of the ventralizing factors purmorphamine and $\mathrm{SHH}$ was compared at different concentrations. Subsequently, the impact of various purmorphamine administration intervals was determined by gene expression analysis. Neuronal phenotypes were characterized by immunofluorescence stainings and the functionality was assessed by neurophysiological recordings.

\section{Comparison of the Rostro-Ventralization Potency Between Purmorphamine and Sonic Hedgehog}

First, we evaluated the suitability of the small molecule purmorphamine for ventral telencephalic differentiation and thus for substitution of the recombinant protein $\mathrm{SHH}$. The latter 

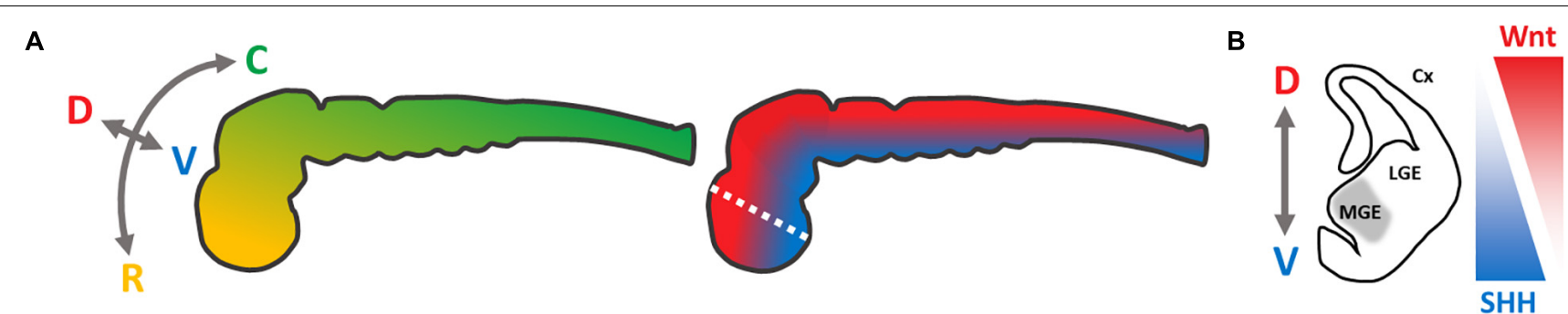

FIGURE 1 | Schematic presentation of neural axes during neurogenesis of the central nervous system, modified from Petros et al. (2011). (A) Color-coded visualization of the rostro-caudal (yellow-green) and dorso-ventral (red-blue) axes of the neural tube; C, caudal; D, dorsal; R, rostral; V, ventral. (B) Coronal section of the left hemisphere (white dotted line in $\mathbf{A}$ ) of the telencephalon, to visualize the targeted regional identity of the medial ganglionic eminence (gray). $\mathrm{SHH}-$ Wnt-pathway activity is indicated in triangles. CX, cortex; LGE, lateral ganglionic eminence; MGE, medial ganglionic eminence.

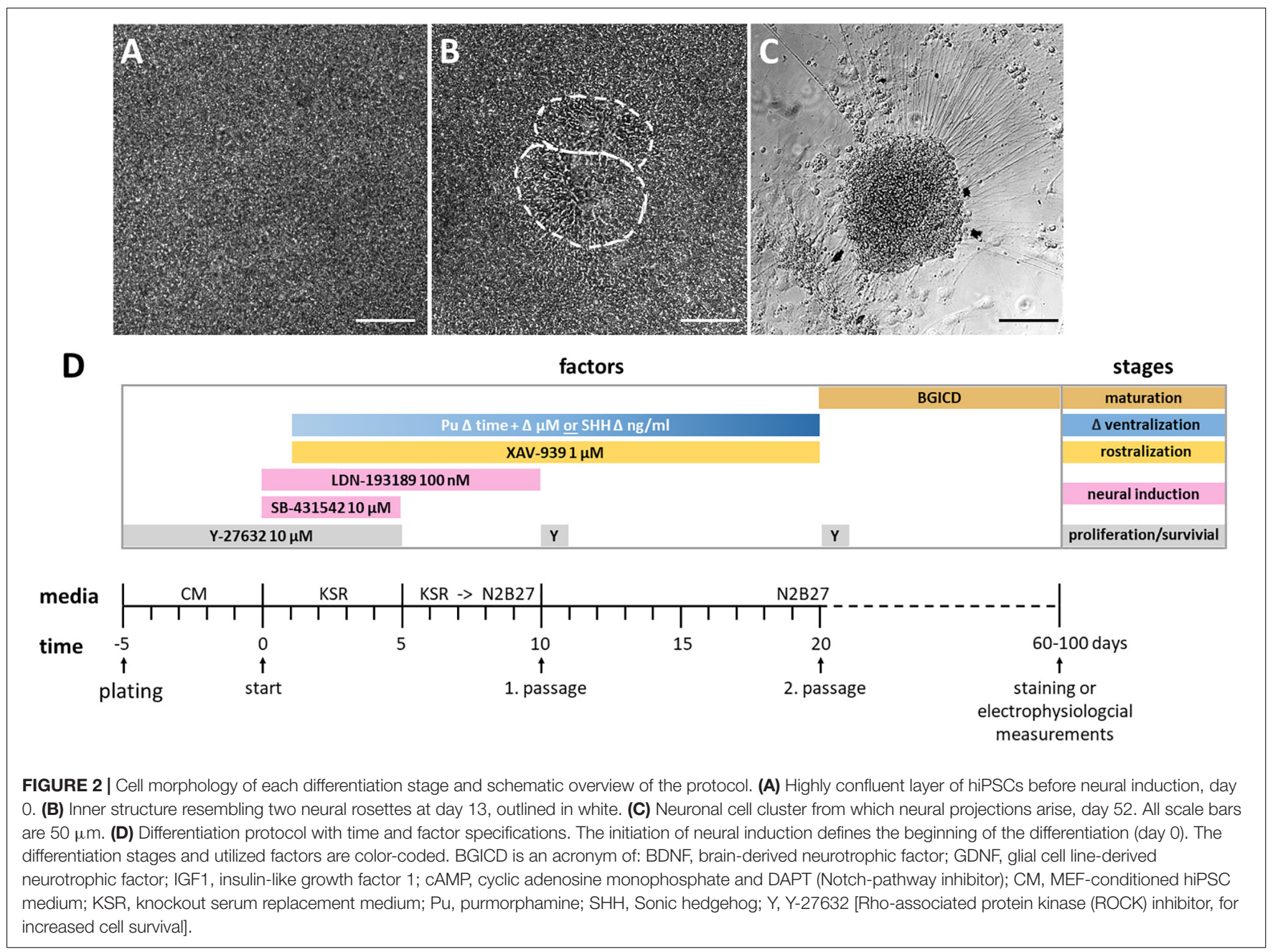

is a crucial signal peptide for the pattering and specification of the MGE in vivo (Xu et al., 2005). To this end, either purmorphamine $(\mathrm{Pu})$ or $\mathrm{SHH}$ were administered for 15 days from day 5 on (Figure 3A). The concentrations were selected to promote either an LGE $(\mathrm{Pu} 0.5 \mu \mathrm{M}$ or SHH $200 \mathrm{ng} / \mathrm{ml})$ or an MGE (Pu $1.5 \mu \mathrm{M}$ or SHH $1000 \mathrm{ng} / \mathrm{ml}$ ) identity (Ma et al., 2012; Liu et al., 2013b). On day 20, the ventralizing efficiency was assessed using gene expression analysis. Along the rostro-caudal patterning axis (Figure 3B), the expression levels of the forebrain marker FOXG1 increased non-significantly after the exposure of both ventralization factors (Pu and $\mathrm{SHH}$ ) compared to nonpatterned cells (control; Ctr). For EMX2, a cortical marker, the expression decreased non-significantly in treated cells in a concentration-dependent manner, with a stronger effect after $\mathrm{Pu}$ administration than after SHH. For the rhombencephalic transcription factor KROX20, the gene expression decreased 
A

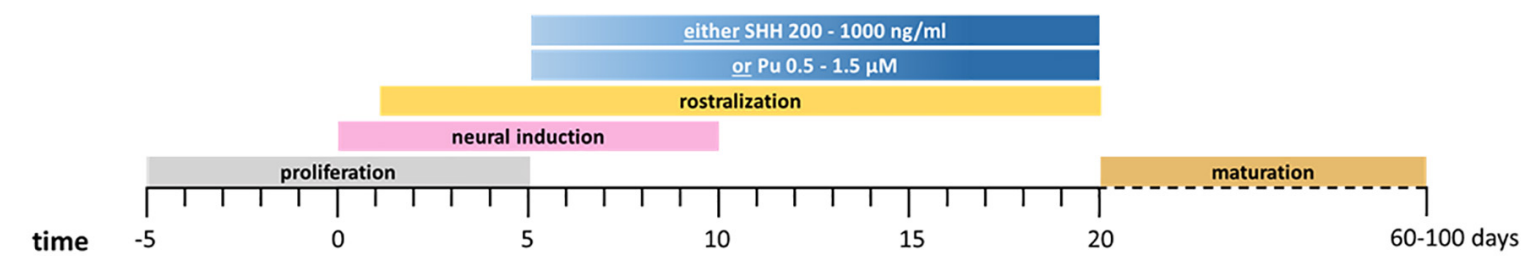

B

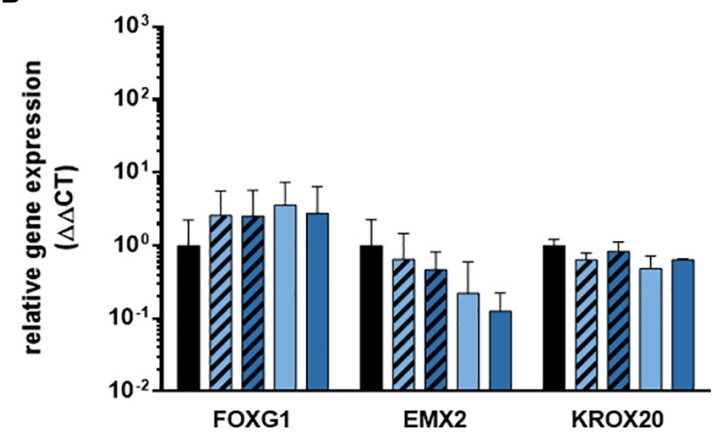

C

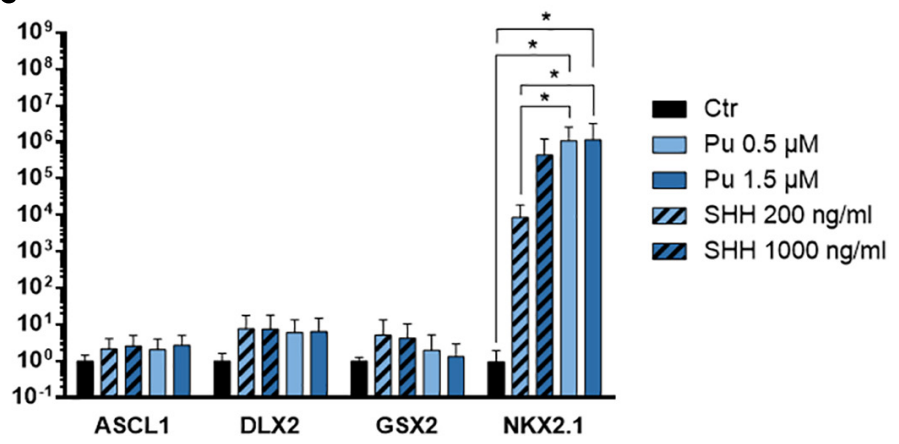

FIGURE 3 | Verification of the most effective ventralization morphogen. (A) Differentiation protocol. Gene expression analysis of either purmorphamine- or Sonic hedgehog-treated cells relative to non-treated samples along the rostro-caudal (B) and dorso-ventral (C) axis, at day 20; $n=$ three to five differentiations, three hiPSC lines. Statistical analysis: two-way ANOVA, correction for multiple testing by the Tukey method, error bars depict the SEM. Significant with $p$-value $<0.05$ (*).

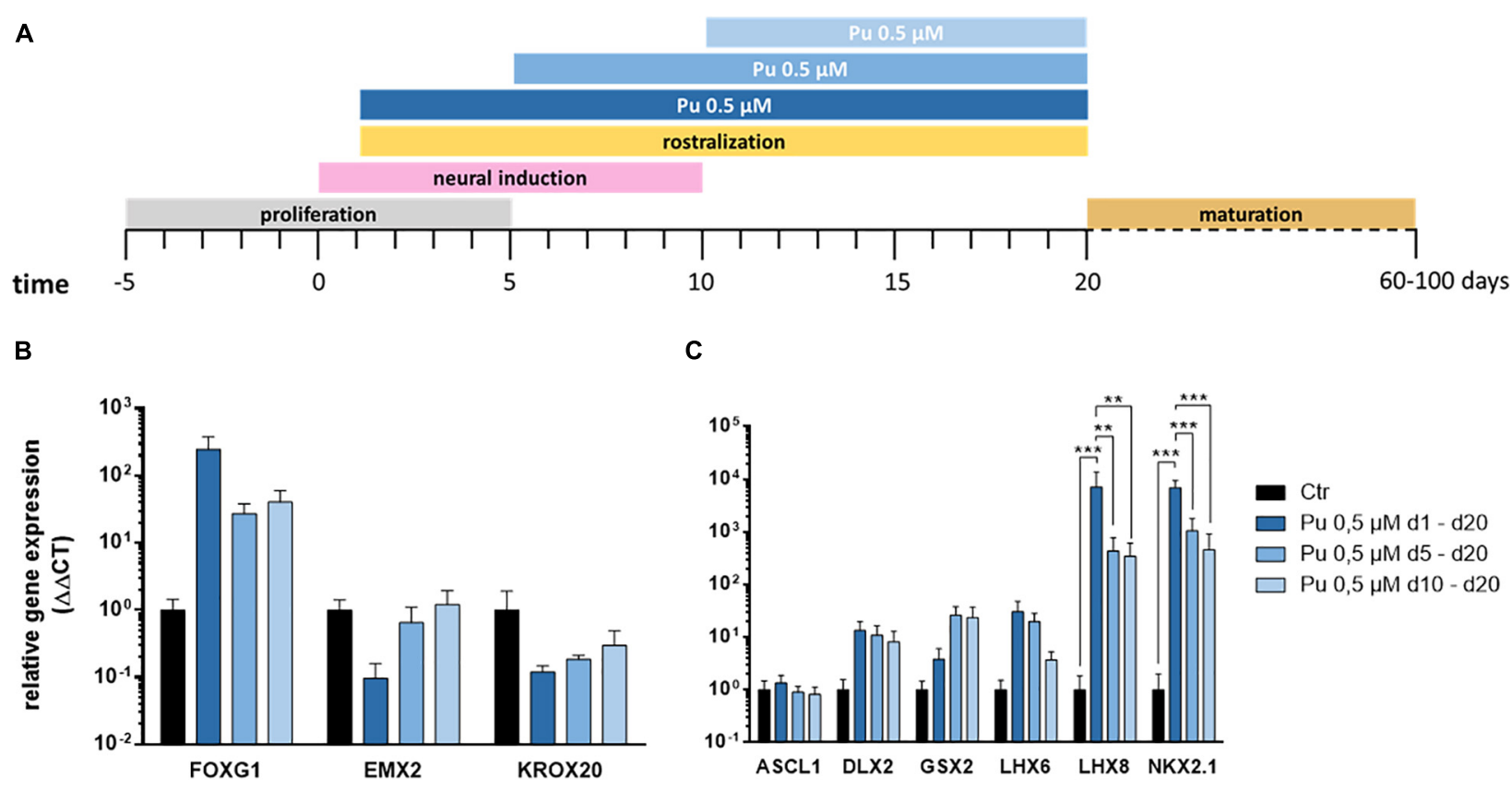

FIGURE 4 | Screening for most effective timing for the application of purmorphamine. (A) Different time intervals for ventral patterning. After regionalization (day 20) the rostro-caudal (B) and dorso-ventral (C) identity was assessed, Pu-treated values are relative to Ctr; $n=$ four differentiations, four hiPSC lines. Statistical analysis: two-way ANOVA, correction for multiple testing by the Tukey method, error bars correspond to the SEM. Significant with $p$-value $\left.<0.005{ }_{(\star \star}\right),<0.0005\left(^{(\star \star)}\right)$.

non-significantly after ventralization $(\mathrm{Pu}$ and $\mathrm{SHH})$ compared to Ctr. Along the dorso-ventral axis (Figure 3C), the expression levels of the pan-ganglionic eminence (pan-GE) markers ASCL1 and DLX2 increased non-significantly after ventralization. Also the expression level of the LGE marker GSX2 increased after treatment, although the effect gradually diminished with higher concentrations. Strikingly, the mRNA level of the MGE marker NKX2.1 was significantly elevated in Pu-treated cells compared to Ctr and to SHH-treated $(200 \mathrm{ng} / \mathrm{ml})$ cells. Of note, the NKX2.1 expression was only slightly elevated after $1.5 \mu \mathrm{M} \mathrm{Pu}$ administration compared to $0.5 \mu \mathrm{M}$ treated cells, suggesting a saturation plateau. The results of the statistical analysis are shown 
in Supplementary Table 5.1. Because we aimed to generate cell populations with the highest MGE identity, we focused on $\mathrm{Pu}$ as a ventralization factor and $0.5 \mu \mathrm{M}$ as working concentration for the following experiments to avoid possible oversaturation effects at higher concentrations.

\section{Determination of Optimal Timing of Purmorphamine Administration}

After verifying the suitability of $\mathrm{Pu}$ as a potent ventralization morphogen and its most promising concentration $(0.5 \mu \mathrm{M})$, we aimed to determine the optimal timing for ventralization. For this purpose, three different ventral patterning time points (day 1,5 , and 10) with decreasing duration $(19,15$, and 9 days) were evaluated (Figure 4A).

The corresponding gene expression analysis (day 20) revealed - along the rostro-caudal axis - for FOXG1 a nonsignificant increase after the earliest treatment compared to Ctr while the effect declined with later ventral regionalization (Figure 4B). In line with this, a clear time dose-effect was evident for the cortical (EMX2) and the hindbrain (KROX20) markers, as the expression decreased with earlier ventral regionalization (Figure 4B). Along the dorso-ventral axis, the cholinergic (LHX8), GABAergic (LHX6), pan-GE (DLX2), and MGE (NKX2.1) markers displayed a temporal dosage effect: longer and earlier ventralization intervals revealed higher expression levels (Figure 4C). In contrast, the LGE marker GSX2 displayed an inverse temporal dosage effect, with non-significantly higher mRNA levels after later and shorter ventralization. Strikingly, the expression levels were significantly upregulated for NKX2.1 and LHX8 after the earliest onset (d1) of rostro-ventralization compared to later treatments and Ctr. The underlying statistical analysis is listed in Supplementary Table 5.2. Notably, the above-mentioned findings could be observed in all cell lines (see Supplementary Figures 1, 2).

Subsequently, hierarchical cluster analysis was performed for each experimental setup to determine the most appropriate patterning regime for generating MGE-specific fates (Figure 5). In the first differentiation regime ( $\mathrm{Pu}$ vs. $\mathrm{SHH}$ ), the gene clustering (top side) diverged first EMX2 and KROX20 from all other genes (Figure 5A). When looking at the standard scale, both genes are downregulated the most after both $\mathrm{Pu}$ treatments $(\mathrm{Pu}$ 0.5/1.5 $\mu \mathrm{M})$. The next clade subdivided NKX2.1 and FOXG1 from the remaining ganglionic marker genes (GSX2, ASCL1, and DLX2) corresponding to their transcription level per treatment type. On the other hand, the ventralization regimes (left panel) separated into treated and untreated conditions, while the ventralizing subgroups diverged between $\mathrm{SHH}$ and $\mathrm{Pu}$ and interestingly not into higher and lower morphogen concentrations. In the second differentiation regime $(\mathrm{Pu}$ time intervals), the first clade first discriminated in genes that were either downregulated by the ventralization regimes (EMX2 and KROX20) or displayed a different time window for elevated expression levels (GSX2) (Figure 5B). In the other clade, the remaining genes were grouped that were most strongly expressed after the earliest and longest $\mathrm{Pu}$ treatment $(\mathrm{d} 1-\mathrm{d} 20)$. Again, the ventralization regimes first clustered between treated and untreated conditions. The following clade separated the intermediate $\mathrm{Pu}$ treatment duration $(\mathrm{d} 5-\mathrm{d} 20)$ from all other $\mathrm{Pu}$ regimes corresponding to the GSX2 expression level. The clustering revealed the importance of the correct morphogen type, as well as the patterning timing for the aimed cell identity. In general, purmorphamine appears to be more suitable to promote an MGE-like identity than SHH. In particular, the earliest and longest $\mathrm{Pu}$ treatment led to the most substantial enrichment of forebrain (FOXG1), pan-GE (ASCL1 and DLX2), MGE (NKX2.1), cholinergic (LHX8), and GABAergic (LHX6) markers, while cortical (EMX2) and hindbrain (KROX20) regionalization was restricted in vitro. Of note, in a short ventralization time window $(\mathrm{Pu} 0.5 \mu \mathrm{M}$ or $\mathrm{SHH} 200 \mathrm{ng} / \mathrm{ml} \mathrm{d} 5-\mathrm{d} 20$ ), a specific lateral ganglionic (GSX2) identity seems to be more pronounced. Upon later ventralization ( $\mathrm{Pu} \mathrm{d} 10-\mathrm{d} 20)$, or $\mathrm{SHH}$ administration, cortical (EMX2) and rhombencephalic (KROX20) identities become more prominent compared to $\mathrm{Pu} \mathrm{d} 1-\mathrm{d} 20$. The clustered data are listed in Supplementary Table 5.3.

In summary, the ventral patterning regime $(\mathrm{Pu} 0.5 \mu \mathrm{M} \mathrm{d1-}$ $\mathrm{d} 20$ ) with the earliest onset - during neural induction - and the highest $\mathrm{Pu}$ concentration led to the strongest upregulation of MGE, cholinergic, and GABAergic marker genes on mRNA-level.

\section{Qualitative Immunofluorescence Characterization After Terminal Differentiation Confirms Retention of Induced Cellular Regional Identity}

Having quantitatively determined the effective rostro-ventral patterning condition at the progenitor cell stage, we aimed to verify which neuronal identity the cells possessed after at least additional 30 days of final differentiation. Representative immunofluorescence images display the effect of rostroventralized cells in comparison to non-patterned samples. Control cells, which were only neurally induced, did not show any noticeable fluorescence staining of the MGE marker NKX2.1 (Figure 6A). In contrast, this transcription factor was extensively detected in Pu-treated cells (Figure 6B), which is in line with our expression data. The region in which NKX2.1 is present in the brain of 12.5-day-old mouse embryos (Du et al., 2008) is schematically shown in the right panel of Figure 6. Furthermore, rostro-ventral patterning resulted in a substantial reduction of TBR2 compared to unpatterned cells (Figures 6C,D). TBR2 is a transcription factor that is highly expressed in neural precursor cells of the neocortex (Englund et al., 2005). Therefore, we could verify on protein level that the patterning changed - as expected the regional identity from a cortical to an MGE-like phenotype.

Further immunofluorescence stainings were performed to characterize the differentiated cells in more detail. Figure 7 shows immunostained cells harboring a BFCN identity. A proportion of NKX2.1-positive cells was also ChAT-positive (Figures 7A,D). Choline acetyltransferase (ChAT) is responsible for the biosynthesis of the neurotransmitter acetylcholine, from acetyl-coenzyme A and choline (Cho et al., 2014), and thus necessary for the formation of cholinergic interneurons. Additional evidence for a BFCN-identity is the co-expression of p75 with ChAT (Figure 7B). The neutrophin receptor p75 
A

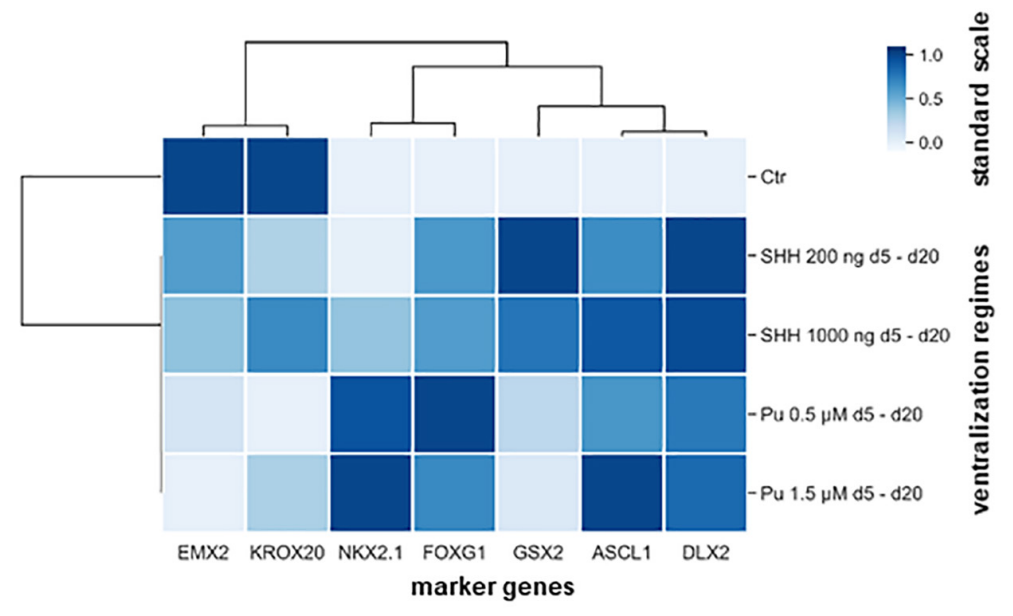

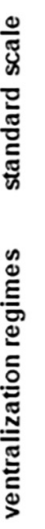

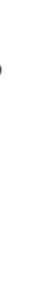

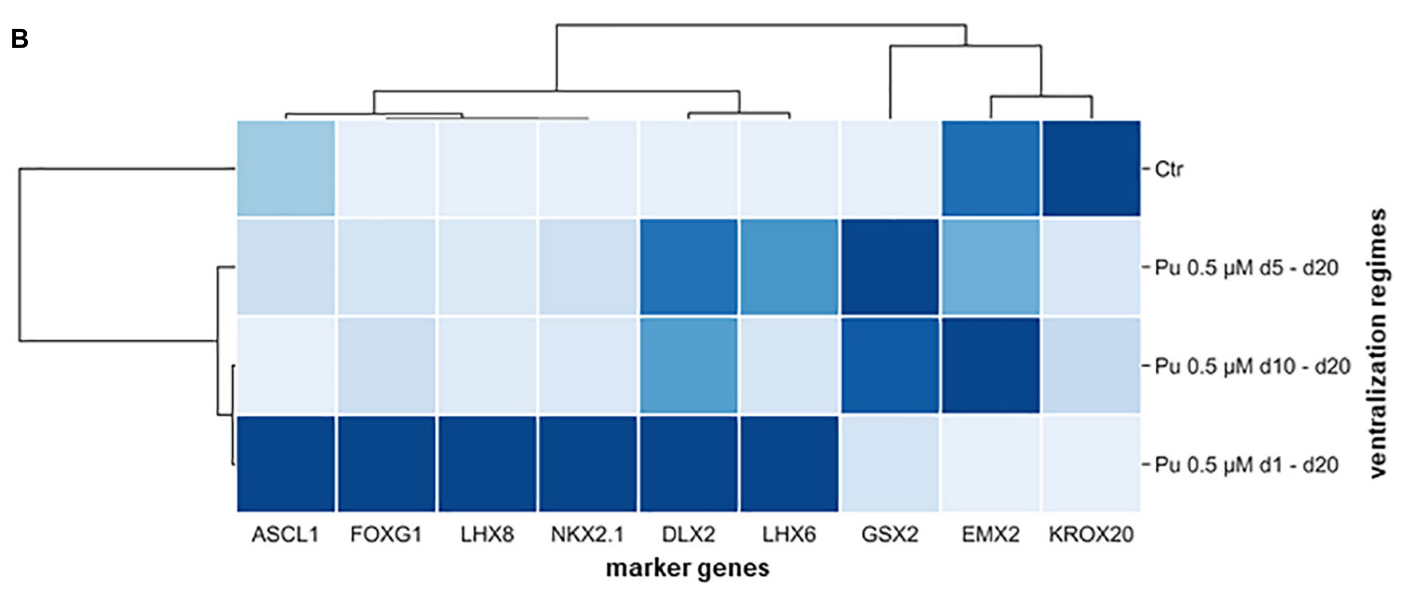

FIGURE $\mathbf{5}$ | Hierarchical cluster heatmaps segregating the gene expression profiles (transverse axis) from the expression signature (Iongitudinal axis) according to applied rostro-ventralization regimes. (A) The first cluster map is based on RT-qPCR datasets from the comparison between Pu vs. SHH. The gene expression profiles were clustered into four groups: most downregulated after Pu treatment (EMX2 and KROX20), most upregulated after Pu treatment (NKX2.1 and FOXG1), most upregulated after SHH $200 \mathrm{ng} / \mathrm{ml}$ administration (GSX2), and in general upregulated after rostro-ventralization (ASCL1 and DLX2). Furthermore, the ventralization regimens appeared to cluster by morphogen type rather than by applied concentration. (B) The second cluster map is based on RT-qPCR datasets from different Pu treatment intervals. Here, the gene expression profiles clustered in three major groups: most elevated after the earliest and longest purmorphamine administration (d1-d20) (forebrain, pan-GE, GABAergic, and MGE-specific markers), most upregulated after the intermediate purmorphamine (d5-d20) interval (LGE); most downregulated after the earliest and longest purmorphamine administration (d1-d20) (cortical and hindbrain). Likewise, the ventralization regimes clustered whether they promoted an MGE-like expression signature or resulted in an LGE-like identity. The standard scale was calculated for each gene (column).

encodes for a surface marker of mature BFCNs (Schnitzler et al., 2008). Furthermore, the neuronal identity of ChAT-positive cells was validated by coexpression of MAP2 (Figure 7C). The microtubule-associated protein 2 is involved in microtubule stabilization (Qiang et al., 2006) and intracellular trafficking (Gumy et al., 2017); thus essential for the cytoarchitecture of neurons. The cholinergic identity was further verified by the detection of the vesicular acetylcholine transporter (VACHT) in synaptic boutons (Figure 7E).

In addition to cholinergic interneurons, GABAergic interneurons also originate from the MGE (Marin et al., 2000). In keeping with our previous expression data, we observed the appearance of GABAergic cells. Compared to non-patterned cells (Figure 7F), a much higher proportion of GABA- and MAP2-positive cells with a higher amount of projections was observed in rostro-ventralized samples (Figure 7G). Of note, cells at the periphery of cell clusters exhibited more often a mature phenotype as well as a more mature morphology (e.g., longer neurites) than cells within cell clusters (Figures 7B-D,F,G). Overall, these data lead to the notion that our hiPSC-derived MGE-like populations included cholinergic as well as GABAergic neurons with a mature basal forebrain identity.

\section{Electrophysiological Characterization of hiPSC-Derived Cholinergic Neurons}

To investigate the neuronal activity of our generated cells, wholecell patch-clamp measurements were performed on cells kept for 96 days in vitro. The selection criterion for recordings was the morphology of the cells, which should correspond to that 


\section{A unpattered}

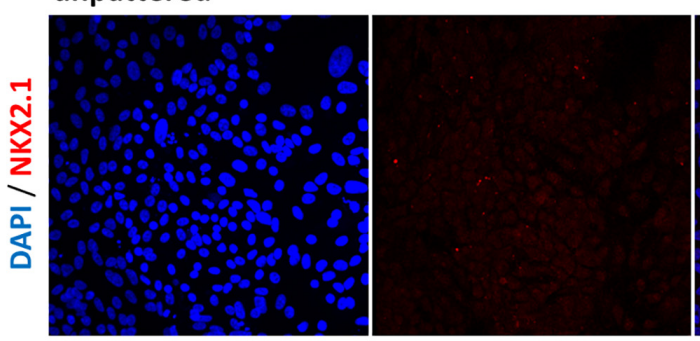

B Pu 0,5 $\mu \mathrm{M}+$ XAV-939 $1 \mu \mathrm{M}$
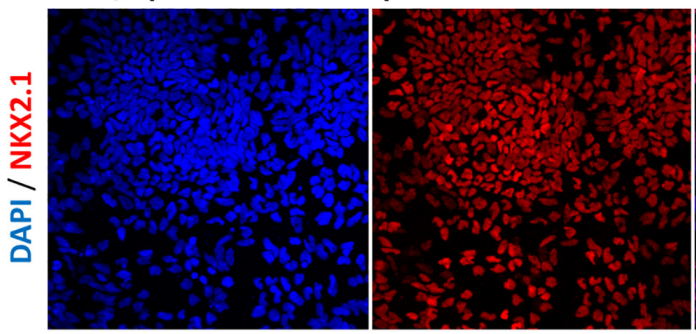

C unpattered

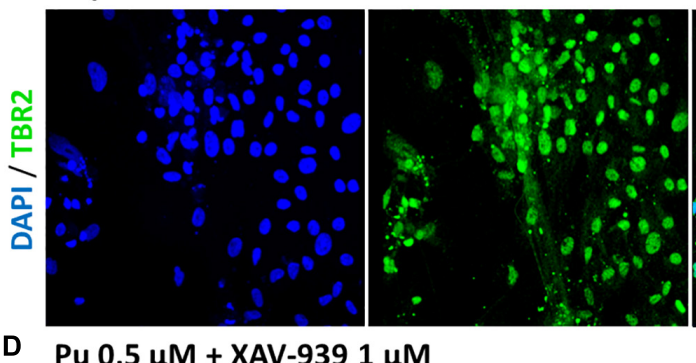

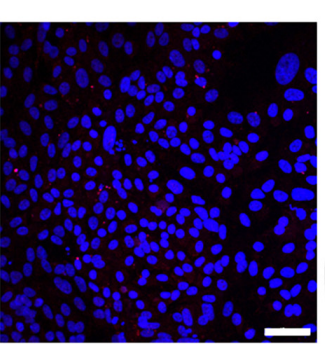

E12.5-14.5
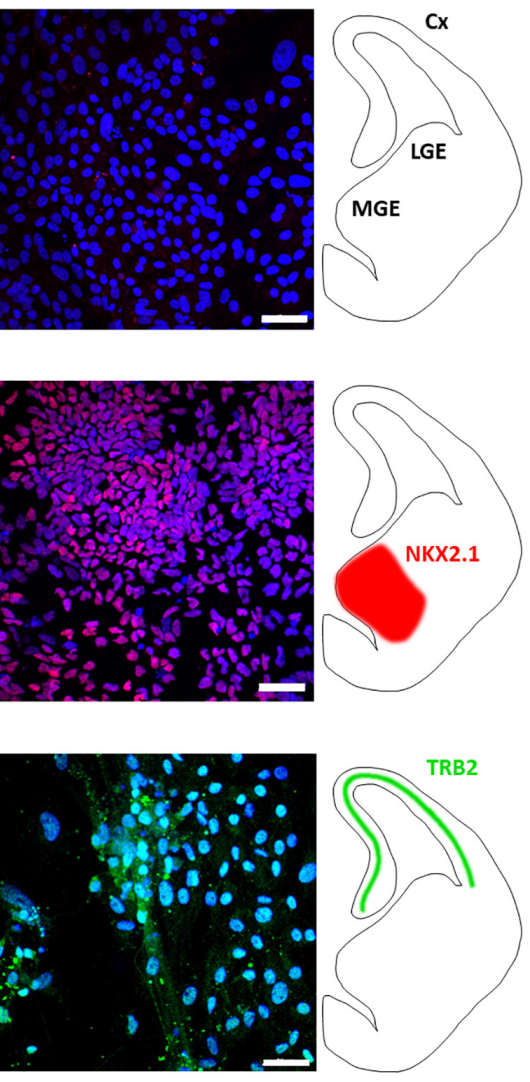
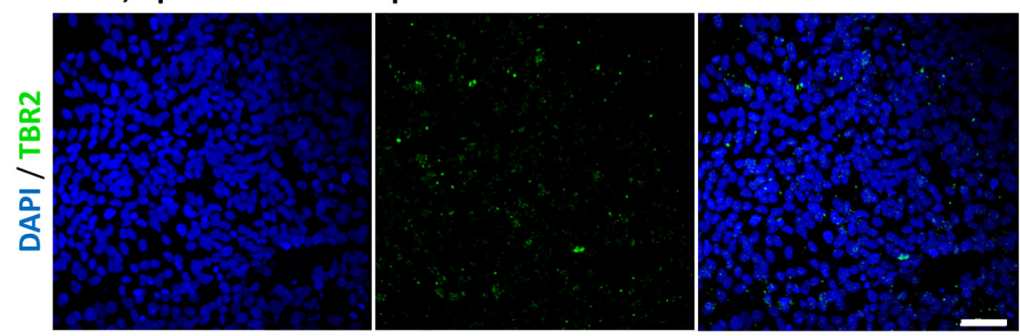

FIGURE 6 | Immunofluorescence images of 55 days in vitro (35 days after final maturation) neuronal populations. (A) In non-regionalized cells, the MGE-specific marker NKX2.1 was not detected, whereas (B) rostro-ventralized populations retained their adopted MGE identity after final maturation. (C) In contrast, the unpatterned cells exhibited a cortical identity (TBR2) which could not be identified in the rostro-ventralized populations (D). The first panel shows nuclear staining with DAPI (blue); the second panel shows protein detection of NKX2.1 (red) or TBR2 (green); the third panel shows the overlay of the first two panels; the last column schematically shows the expression region of NKX2.1 and TBR2 in coronal sections of the left hemisphere in a 12.5-14.5-day-old mouse embryo (Englund et al., 2005; Du et al., 2008). Cx, cortex; LGE, lateral ganglionic eminence; MGE, medial ganglionic eminence. Scale bars are $40 \mu \mathrm{m}$.

of cholinergic neurons: a fusiform soma, with a diameter of 20-50 $\mu \mathrm{m}$, giving rise to thick dendrites, which branched into finer processes of higher orders. The cholinergic identity of some recorded cells was confirmed by post hoc immunostainings: neurons on two coverslips were filled during recording this way ( $\sim 5$ neurons per coverslip). After fixation and incubation, three of these neurons could still be identified. All were positive for ChAT as well (Figure 8A). In the first measurement, a current-voltage relation was determined (Figure 8B). For this, holding potentials were increased in increments of $10 \mathrm{mV}$ steps from -70 to $+40 \mathrm{mV}$. The presence of voltage-gated potassium outward and sodium inward channels was shown by short influxes (sodium) and long effluxes (potassium) of cations after depolarization. The current maxima were normalized according to the cell membrane capacitance $(\mathrm{pA} / \mathrm{pF})$. Concerning the potassium outward current, the highest current density average $(152.73 \mathrm{pA} / \mathrm{pF})$ was measured at a membrane potential of $40 \mathrm{mV}$. The highest current density average for sodium influx was $-114.58 \mathrm{pA} / \mathrm{pF}$ at an applied voltage of $-10 \mathrm{mV}$. In addition to the current-voltage plot, we characterized the action potentials and synaptic activity of the cells. Besides single action potentials (sAP), trains of APs (tAP) were also monitored, 

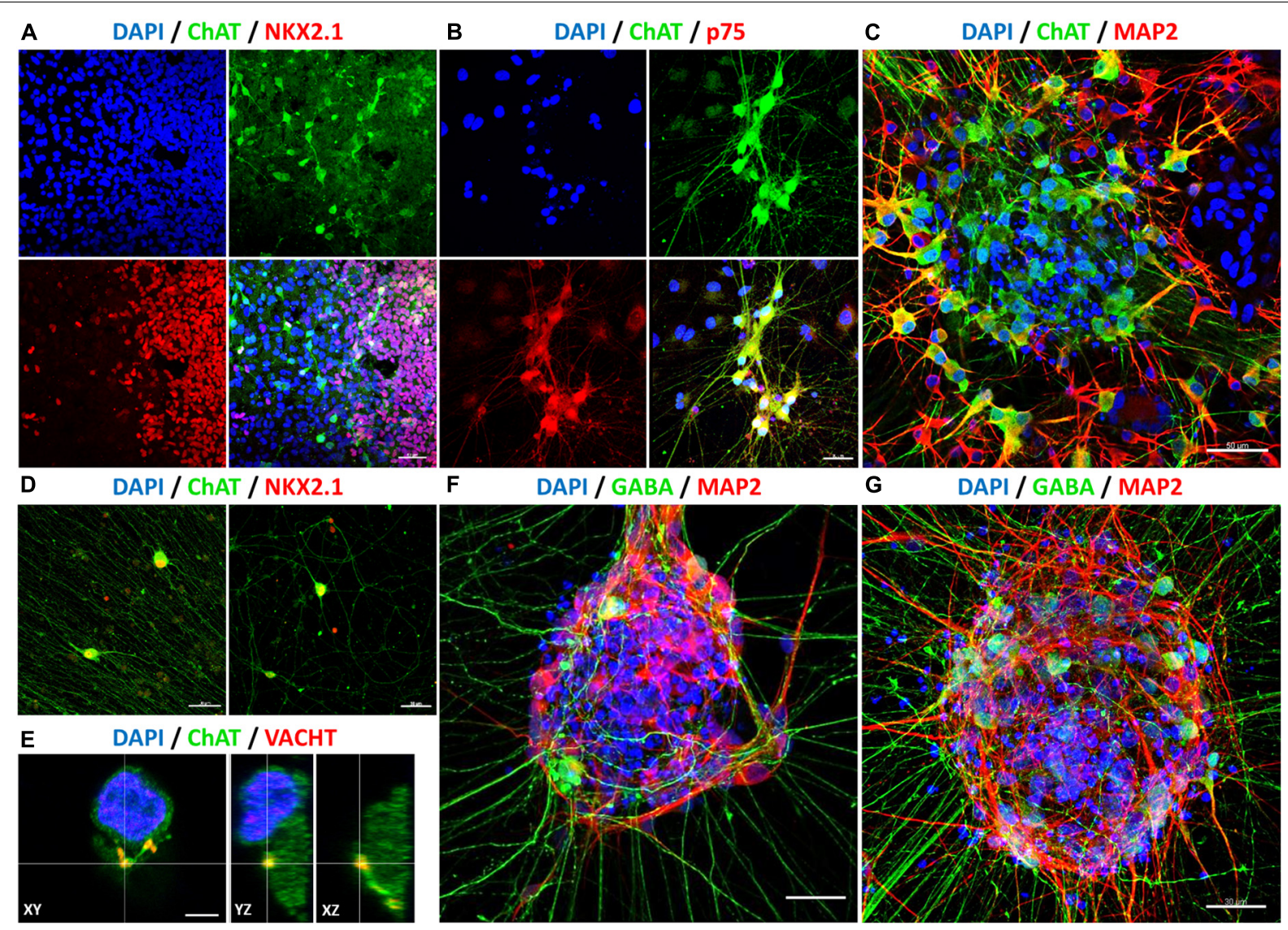

FIGURE 7 | Determination of neuronal identity with immunofluorescence stainings after 60 days in vitro (40 days after final maturation). After rostro-ventralization, the presence of BFCNs was confirmed by coexpression of ChAT (green: A-E), with NKX2.1 (red: A,D), p75 (red: B), MAP2 (red: C), and VACHT (red: E). Compared to unpatterned samples (F), qualitatively more GABA-positive neurons and neurites (GABA: green, MAP2: red) were observed in patterned cell populations (G). Nuclei were stained with DAPI (blue). Scale bars: $40 \mu \mathrm{m}$ (A), $30 \mu \mathrm{m}$ (B,D,F,G), $50 \mu \mathrm{m}$ (C), and $5 \mu \mathrm{m}$ (E).

which are a characteristic of mature neurons (Figure $\mathbf{8 C}$ ). Large postsynaptic currents (PSCs) were observed in $18.2 \%$ of all measured cells with a frequency of $0.15 \pm 0.06 \mathrm{~Hz}$ (Figure 8D). These PSCs were AP-dependent, indicating signal transductions from inter-cell communication. Miniature PSCs triggered by spontaneous vesicle releases were recorded in $43.6 \%$ of all measured cells (Figure 8D) with a frequency of $0.51 \pm 0.09 \mathrm{~Hz}$. Finally, spontaneous APs were also observed in $32.7 \%$ of the cells, which had a frequency of $1.74 \pm 0.48 \mathrm{~Hz}$ (Figure 8D). Active and passive membrane properties are summarized in Supplementary Table 5.4. In sum, the gene expression pattern and immunochemical stainings contribute to the notion that our newly established protocol enables the generation of BFCNand GABAergic-like neurons from hiPSC. In addition, the functional maturity of the neuronal population was confirmed by electrophysiological measurements.

\section{DISCUSSION}

Human in vitro models, such as hiPSC-derived BFCNs, provide an excellent platform to investigate neurological disorders, such as Alzheimer's disease or isolated dystonias. However, the number, as well as the physiological maturity of BFCNs, differentiated from human sources is limited and the regional identity of the generated neurons is not well characterized (Ochalek et al., 2016). Therefore, we systematically tested for the most effective striatal regionalization parameters (mimicking MGE environment during embryogenesis) to evaluate MGEspecific gene expression.

Before the regionalization was initiated, neural cell fate was induced using dual SMAD inhibition (Chambers et al., 2009). When NPCs are not further regionalized, they acquire a telencephalic identity, regardless of the protocol used to initiate neural induction (Kim et al., 2014). This observation is consistent with the assumption that the first NPCs have a dorsal-telencephalic identity a priori during neural induction in vertebrates (Muñoz-Sanjuán and Brivanlou, 2002). These nonregionalized cells served as reference cells for gene expression and immunofluorescence analyses. As shown in other publications, telencephalic identity can be further enhanced by rostralization when the Wnt signaling pathway is blocked via the small molecule XAV-939 (Maroof et al., 2013) or via the recombinant protein DKK1 (Eiraku et al., 2008; Nicholas et al., 2013). Also, 
A

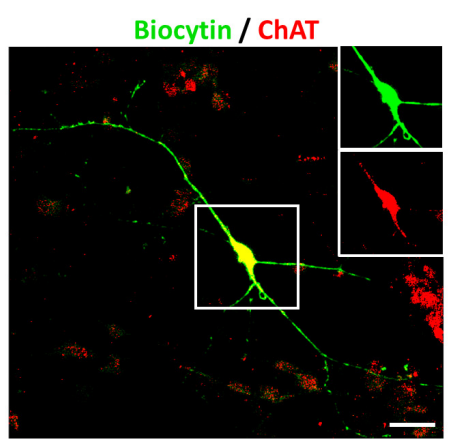

C

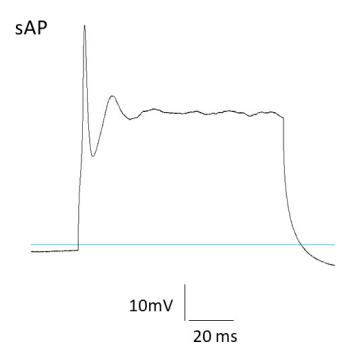

tAP

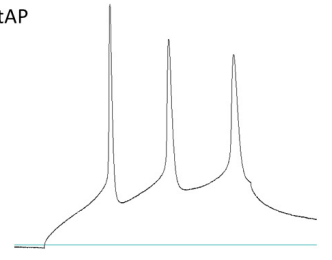

D
B
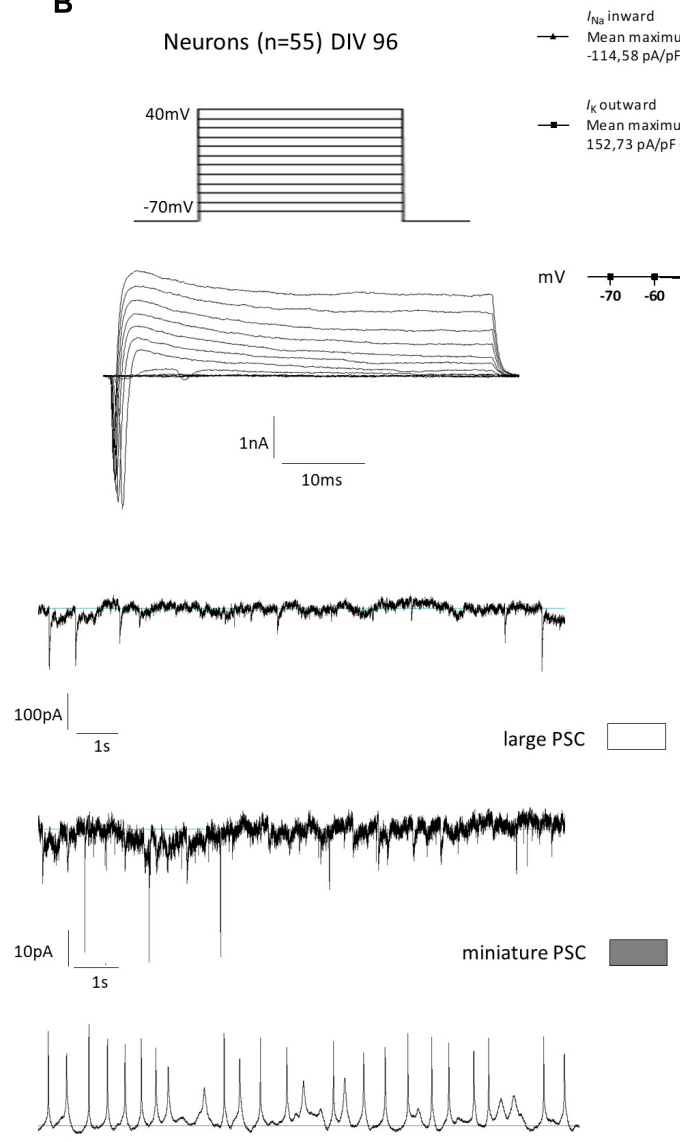

$20 \mathrm{mV}$

1s

spontaneous APs
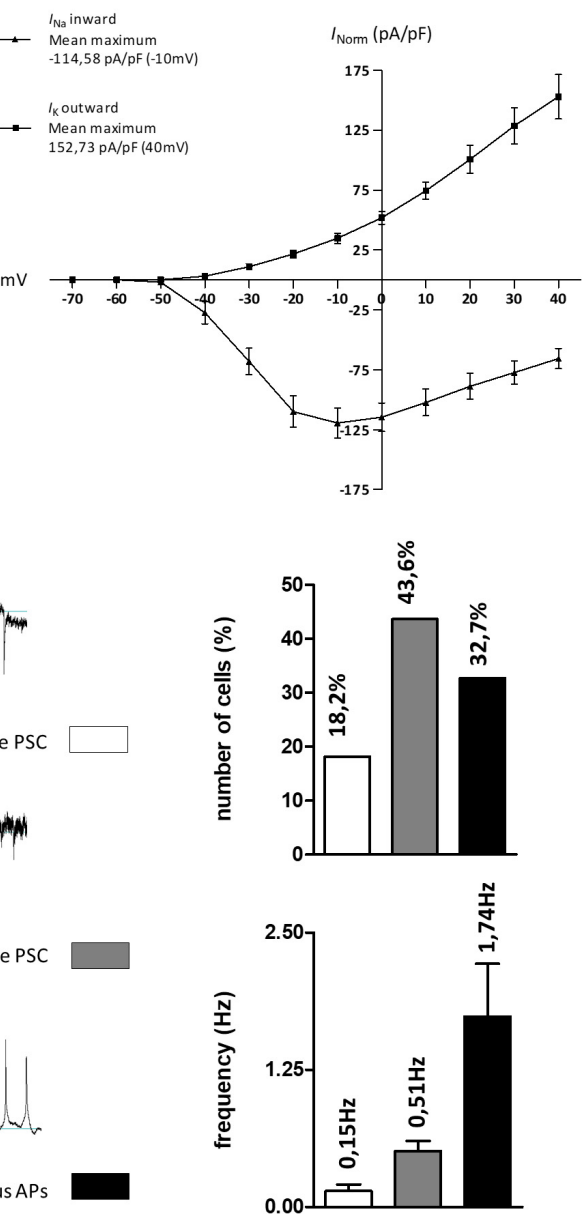

FIGURE 8 | Electrophysiological properties of hiPSC-derived cholinergic neurons 96 days after the onset of differentiation. (A) Representative image of a large multipolar neuron $(n=55)$ that was selected for patch-clamp studies. For later immunotype characterization some of the recorded cells were marked via biocytin and subsequent streptavidin staining. Insets show biocytin (green) and ChAT (red) staining in the perinuclear region. Scale bar: $20 \mu \mathrm{m}$. (B) Depolarizing steps in stepwise increments of $10 \mathrm{mV}$ from a holding potential of -70 to $+40 \mathrm{mV}$ were performed in the whole-cell voltage-clamp mode to trigger voltage-dependent sodium and potassium currents. (C) Evoked action potentials (AP) were recorded as single APs (SAP) but also as train APs (tAP) typically observed in mature neurons.

(D) Spontaneous activity was observed in the whole-cell recording mode by means of large AP-dependent postsynaptic currents (large PSC; upper figure) in 18.2\% of the cells with a frequency of $0.15 \pm 0.06 \mathrm{~Hz}$. As a result of spontaneous vesicle release, miniature PSCs were recorded in $43.6 \%$ of all recorded cells with a frequency of $0.51 \pm 0.09 \mathrm{~Hz}$. Current-clamp recordings further revealed the firing of spontaneous APs in $32.7 \%$ of the cells with a frequency of $1.74 \pm 0.48 \mathrm{~Hz}$. All values are presented as means \pm SEM.

these neural progenitors can be further regionalized ventrally or dorsally. The ventral specification requires stimulation of the $\mathrm{SHH}$ pathway in addition to Wnt pathway inhibition. This can be facilitated either via the administration of recombinant $\mathrm{SHH}$, or small molecules like purmorphamine (Watanabe et al., 2005; Li et al., 2009; Liu et al., 2013b; Maroof et al., 2013; Nicholas et al., 2013). In contrast to the protocols mentioned above, we aimed to establish an efficient rostro-ventralization patterning protocol suitable for hiPSC; omitting the usage of murine- or human-derived embryonal stem cells.

During the first patterning regime, cells were ventralized with either $\mathrm{Pu}(0.5-1.5 \mu \mathrm{M})$ or SHH (200-1000 ng/ml) 5 days after the initiation of neural induction and rostralization. Two weeks later, we assessed the regionalization along the rostro-caudal and dorso-ventral neuraxes by comparing the gene expression of different marker genes. Evaluation of the expression profiles showed that both morphogens increased the forebrain and ganglionic eminence identity, although only samples after $\mathrm{Pu}$ administration showed a significant increase in the MGE-specific marker NKX2.1. Since the higher $\mathrm{Pu}$ concentration compared to the lower concentration did not result in a significant upregulation of NKX2.1, we focused on $\mathrm{Pu} 0.5 \mu \mathrm{M}$ for the determination of the most favorable timing during ventralization.

To assess when the ventralization patterning is most effective, purmorphamine was administered either at onset, during, or after neural induction. The expression levels of MGE-markers correlated with earlier and longer regionalization time intervals. This finding corresponds to the assumption, that dosage and temporal coordination have a crucial role in ventral identity expression (Fasano et al., 2010). In contrast, expression levels of 
EMX2 (cortical), KROX20 (hindbrain), as well as GSX2 (LGE), increased with later regionalization. Strikingly, we could confirm the abovementioned observations by employing unsupervised hierarchical linkage clustering of our gene expression data sets. Thus, we confirmed that different optimal time intervals exist for specific regionalizations with the MGE possessing an earlier time window than LGE. In conclusion, the substantial increase in telencephalic ventral markers NKX2.1, LHX6, and LHX8 after the conducted patterning reflects the regionalization of our human-derived cells into a MGE identity, potentially reflecting the specified in vivo neurogenesis in vitro.

When comparing the relative gene expression levels between the two experimental setups, there are - in some cases noticeable differences for the same genes. Since the controls were not patterned, spontaneous differentiation occurred, the direction of which could not be influenced. In particular, for controls, the expression levels of LHX8 and NKX2.1 were sometimes detectable only at very late CT values (see Supplementary Figure 1). On the other hand, the expression levels within each treatment condition of the target genes varied mostly within one to two logarithmical scales across all cell lines (see Supplementary Figure 2), demonstrating that the collected gene expression data are robust within the experimental setups. With this, we explain the divergent relative gene expression levels for some genes between both setups.

After the most efficient rostro-ventral patterning protocol for the progenitor cell stage was evaluated, the identity of matured cells was qualitatively determined in comparison to nonregionalized cells by immunofluorescence analysis. Remarkably, the MGE-like identity remained after regionalization - with nearly homogenous NKX2.1 expression, whereas non-patterned cells were negative for NKX2.1. In contrast, the control cells exhibited a cortical phenotype (high number of TBR2-positive cells), whereas this phenotype was virtually absent in patterned cells. This indicates that the cells retained their cell fate, as previously determined by gene expression analysis. Upon detailed characterization of the MGE identities, we found that a large number of NKX2.1 positive cells co-expressed ChAT, p75, and MAP2 (cholinergic neurons) or GABA and MAP2 (presumably GABAergic interneurons). Therefore, we verified the phenotype of BFCNs and GABAergic neurons (Liu et al., 2013b), which was previously validated on the mRNA level. By simultaneously initiating a neural and rostro-ventral cell fate, we were able to facilitate an MGE-like niche in vitro that served as a reservoir for the development of BFCNs and GABAergic interneurons, thereby specifically mimicking the in vivo neurogenesis of these cell types (Sussel et al., 1999). However, we found that the majority of cells showing a mature phenotype to be positioned at the periphery of cell clusters, whereas in cell clusters mature identities were detected to a lesser extent. A possible reason for this observation could be that the cell clusters serve as proliferative niches, from where the cells emigrate and eventually mature. Ultimately, this is consistent with the in vivo differentiation of striatal interneurons, which develop from the MGE. As differentiation progresses in the embryonic brain, the neurons migrate and mature into the striatum and cortex, respectively (Marin et al., 2000).
Finally, we showed that our differentiated MGE-like cells generated action potentials and synaptic activity. The sodium and potassium current amplitudes corresponded to forebrain interneurons differentiated from 8 to 12 weeks (Nicholas et al., 2013). Furthermore, we observed that $18 \%$ of cells had large PSCs and $44 \%$ of cells showed miniature PSCs. The generation of spontaneous action potentials was observed in $33 \%$ of the cells. Collectively, these functional data are indications for electrophysiologically active cells. However, the percentage of PSC- and spontaneous tAP-positive cells may increase after prolonged maturation (Nicholas et al., 2013). Besides, the co-cultivation of glia cells may also lead to higher synapse density and elevated electrophysical activity (Boehler et al., 2007; Nicholas et al., 2013). Further studies could establish CRISPR-Cas9-generated BFCN-reporter lines, which would enable a precise electrophysiological analysis of the corresponding cell type.

In contrast to recent studies, our patterning regime omitted the use of non-adherent approaches, while simultaneously inhibiting the Wnt-pathway during neuralization and ventralization (Ihnatovych et al., 2018; Muñoz et al., 2020). Plating cells under adherent conditions with constant numbers, increase the reproducibility and uniformity of the differentiation experiments in contrast to the formation of embryoid bodies, a process that is more difficult to control. Although more straightforward to operate to non-adherent protocols, we were able to obtain high enrichments of MGE-like neuronal populations. These neuronal populations showed electrophysiological activities (e.g., spontaneous APs) of mature neurons whose cholinergic identity could be verified by post hoc stainings. Therefore, our approach might be more favorable for future high-throughput examinations compared to non-adherent protocols.

In summary, the timing and the stimulation strength of the SHH pathway are crucial for the emergence of ventral telencephalic identities, like BFCNs and GABAergic interneurons. Therefore, rostro-ventral regionalization should be performed in parallel with neural induction.

\section{MATERIALS AND METHODS}

\section{Expansion of Induced Pluripotent Stem Cell}

As previously described (Seibler et al., 2011; Pauly et al., 2018), hiPSCs were generated from primary dermal fibroblasts. Briefly, fibroblasts were transduced with retroviral vectors to overexpress OCT4, SOX2, cMYC, and KLF4. In total, four hiPSC lines from healthy adult donors (who had given informed consent according to the ethical regulations of the University of Lübeck) were employed for the investigations (see Supplementary Table 3). HiPSC colonies were cultured on irradiated mouse embryonic fibroblasts (MEFs) in hiPSC medium (see Supplementary Table 1.1) and harvested by dissociation with Accutase (Gibco, Carlsbad, CA, United States) for $15 \mathrm{~min}$. For adherent neural induction (Chambers et al., 2009), 120,000 cells $/ \mathrm{cm}^{2}$ were transferred to Matrigel-coated 24-well culture plates (Corning, 
Corning, NY, United States) (Figure 2D). To facilitate the switch from MEF feeder layer to feeder layer-free/Matrigel-based cultivation, hiPSCs were expanded with MEF-conditioned hiPSC medium (CM). In addition, the CM was supplemented with FGF-2 (5 ng/ml; Merck Millipore, Darmstadt, Germany) and the ROCK-inhibitor Y-27632 (10 $\mu \mathrm{M}$; Stemcell Technologies, Vancouver, BC, Canada) for increased cell survival (Watanabe et al., 2007). The generation of CM was described here (Tomishima, 2008). In short, MEFs were plated onto $10 \mathrm{~cm}^{2}$ dishes (at 50,000 cells $/ \mathrm{cm}^{2}$ density) with DMEM supplemented with $10 \%$ fetal bovine serum (HyClone, Cytiva, Marlborough, MA, United States). The next day, the medium was removed and cells were washed with $1 \times$ PBS (Gibco, Carlsbad, CA, United States). Subsequently, $10 \mathrm{ml}$ hiPSC medium per dish were applied. After $24 \mathrm{~h}$, the CM was collected and stored at $-20^{\circ} \mathrm{C}$ until use. The conditioning was carried out twice per MEF plate (in total $20 \mathrm{ml} \mathrm{CM}$ per plate).

\section{Neural Induction, Rostro-Ventralization, and Maturation}

The following section is illustrated in Figure 2D. When the expanded hiPSCs reached $80 \%$ confluency, neural induction (day 0 ) was initiated by the addition of the small molecules SB431542 (10 $\mu \mathrm{M}$; Tocris, Bristol, United Kingdom) as a TGF- $\beta$ inhibitor and LDN-193189 (100 nM; Stemgent, Cambridge, MA, United States) as a BMP-inhibitor in KSR medium. From day 5 to 10 , the KSR medium was progressively replaced every other day with the N2B27 medium (KSR:N2B27 volume:volume ratio in percent; day 5-6 75:25, day 7-8 50:50, day 8-9 25:75, and day 10 0:100) while Y-27632 and SB-431542 were withdrawn. The composition of KSR and N2B27 are listed in Supplementary Tables 1.2, 1.3. For the rostro-ventral patterning experiments, cells were treated with XAV-939 (day 1-20) (1 MM; Stemgent, Cambridge, MA, United States) and with either SHH (day 5-20) (200 or $1000 \mathrm{ng} / \mathrm{ml}$; R\&D Systems, Minneapolis, MN, United States) or with varying concentrations $(0.5$ or $1.5 \mu \mathrm{M})$ and durations (day 1/5/10-20) of purmorphamine (Stemgent, Cambridge, MA, United States). The patterning steps were omitted in controls. On day 10, the cells (preferably neural rosettes) were transferred en bloc (approximately $1 \mathrm{~mm}$ edge length) to Matrigel-coated 12-well culture plates, and Y-27632 (10 $\mu \mathrm{M})$ was added for $24 \mathrm{~h}$. Again, on day 20, samples were transferred en bloc onto poly-D-lysine- (Sigma-Aldrich, St. Louis, MO, United States) and laminin-coated (Roche, Basel, Switzerland) coverslips (Hecht, Sondheim, Germany) into 12well culture plates (Corning, Corning, NY, United States). A subset of cells was employed for gene expression analysis. The plated cells were terminally matured for at least 30 days until immunofluorescence stainings and electrophysiological measurements in N2B27 medium containing BDNF $(20 \mathrm{ng} / \mathrm{ml}$; PeproTech, Hamburg, Germany), GDNF (10 ng/ml; PeproTech, Hamburg, Germany), IGF1 (10 ng/ml; PeproTech, Hamburg, Germany), db-cAMP (500 $\mu$ M; Enzo Life Sciences, Farmingdale, NY, United States), and DAPT (10 $\mu \mathrm{M}$; Tocris, Ellisville, MO, United States). The first three factors are neurotrophins that increased survival and supported neural maturation
(Liu et al., 2013a). The last two factors supported the formation of a mature neural morphology (Kirkeby et al., 2012). Of note, the quality of the generated cells was determined morphologically at least every other day. The proportion of neural rosette-like structures was monitored during rostro-ventral specification. Until the second passage at the latest, an experimental run was rejected if much of the population morphology did not correspond to a dense monolayer with an internal structure resembling neural rosettes (excluding controls).

\section{Gene Expression Analysis}

The RNA extraction and RT-qPCR were conducted as described recently (Pauly et al., 2018; Stengel et al., 2020). In short, cell samples were homogenized (QIAshredder kit, Qiagen, Hilden, Germany) and followed by purification of total RNA (RNeasy Mini Kit, Qiagen, Hilden, Germany). Subsequently, RNA was transcribed to cDNA by the Maxima First Strand cDNA Synthesis Kit for RT-qPCR (Thermo Fisher Scientific, Waltham, MA, United States). Relative gene expression levels were analyzed using the comparative $\Delta \Delta \mathrm{CT}$ method by regular RT-qPCR following the manufacture's protocol for LightCycler FastStart DNA Master SYBR Green I Kit and LightCycler ${ }^{480}$ (Roche, Basel, Switzerland) (for the primer sequence see Supplementary Table 2). Unsupervised hierarchical gene expression and ventralization regime clustering were performed using seaborn (0.11.1) (Waskom, 2021) and the complete linkage method, while the standard scale was calculated for the genes (columns).

\section{Immunofluorescence Staining}

Cells were treated as recently described (Stengel et al., 2020). In detail, cells were washed with $1 \times$ PBS (Gibco, Carlsbad, CA, United States) and then fixed with $4 \%$ paraformaldehyde (Sigma-Aldrich, St. Louis, MO, United States) for $30 \mathrm{~min}$ at room temperature. After repeated washing steps with PBS, non-specific binding sites were blocked for 45 min with PBS containing 5\% normal donkey (Sigma-Aldrich, St. Louis, MO, United States) or goat serum (Invitrogen, Carlsbad, CA, United States), 0.1\% Triton X-100 (AppliChem, Darmstadt, Germany) and 0.01\% $\mathrm{NaN}_{3}$ (Sigma-Aldrich, St. Louis, MO, United States). Primary antibodies were incubated overnight at $4^{\circ} \mathrm{C}$, followed by a washing step $(1 \times 15 \mathrm{~min})$ with washing buffer (PBS with $0.1 \%$ Triton X-100). Secondary antibodies were incubated for $2 \mathrm{~h}$ at room temperature (the employed antibodies are listed in Supplementary Table 4). Both primary and secondary antibodies were diluted in PBS with 1\% normal donkey or goat serum containing $0.1 \%$ Triton X-100 and $0.01 \% \mathrm{NaN}_{3}$. Subsequently, the samples were quenched using Sudan Black $(0.1 \%$, in $70 \%$ ethanol; Sigma-Aldrich, St. Louis, MO, United States) for $15 \mathrm{~min}$ at room temperature. This step reduced autofluorescence by lipofuscin, lipids, triglycerides, and lipoproteins (Oliveira et al., 2010). Subsequently, cells were washed $(3 \times 5 \mathrm{~min}$ with wash buffer and $1 \times 5 \mathrm{~min}$ with PBS). Finally, the samples were mounted with Vectashield containing DAPI (Thermo Fisher Scientific, Waltham, MA, United States) on slides (Menzel Gläser, Braunschweig, Germany). Samples were stored in the dark at $4^{\circ} \mathrm{C}$ until analysis. Imaging was performed using a confocal 
laser scanning microscope (LSM 710, ZEN black software; Zeiss, Jena, Germany).

\section{Electrophysiology}

Electrophysiological measurements were employed as described previously (Stanslowsky et al., 2014). In brief, patch pipettes, made of borosilicate glass (Science Products, Hofheim, Germany), were pulled using a P-1000 (Sutter Instruments, Novato, CA, United States) and filled with an internal solution consisting of $153 \mathrm{mM} \mathrm{KCl}, 1 \mathrm{mM} \mathrm{MgCl}, 10 \mathrm{mM} \mathrm{HEPES}$, $5 \mathrm{mM}$ EGTA, and $2 \mathrm{mM} \mathrm{Mg-ATP,} \mathrm{adjusted} \mathrm{to} \mathrm{pH} 7.3$ with $\mathrm{KOH}(305 \mathrm{mOsm})$ resulting in a resistance of 3-4 M $\mathrm{M}$. The bath solution contained $142 \mathrm{mM} \mathrm{NaCl}, 8 \mathrm{mM} \mathrm{KCl}, 1 \mathrm{mM}$ $\mathrm{CaCl}_{2}, 6 \mathrm{mM} \mathrm{MgCl}$, $10 \mathrm{mM}$ glucose, and $10 \mathrm{mM} \mathrm{HEPES}$, adjusted to $\mathrm{pH} 7.4$ with $\mathrm{NaOH}$ (325 mOsm). Cell fillings were performed comparable to a previous study (Capetian et al., 2018). During cell recordings on two coverslips, biocytin was included in the pipette solution to identify the phenotype of the recorded neurons by fluorescence microscopy. After recordings, the cells were subsequently fixed and streptavidin and immunofluorescence staining against the cholinergic marker ChAT was done. Whole-cell patch-clamp measurement was performed at room temperature using an inverted microscope (Zeiss, Jena, Germany). Only cells with a leakage current of $<100 \mathrm{pA}$ were used for the study. The recordings were filtered by a low-pass filter at $2.9 \mathrm{kHz}$, digitized via an EPC-10 amplifier (HEKA, Lambrecht, Germany) at $10 \mathrm{kHz}$, and analyzed using Patch Master software (HEKA).

\section{Statistical Analysis}

Data were analyzed using GraphPad Prism 6 (GraphPad Software, San Diego, CL, United States). The patterning effect at the mRNA level was compared with a two-factorial analysis of variance (two-way ANOVA), followed by Tukey test for multiple comparisons. The means of expression levels were calculated, along with the standard error of the mean (SEM). Results were considered significant with $p$-values $<0.05$, adjusted $p$-values, and row statistics of the gene expression analyses are shown in Supplementary Tables 5.1, 5.2.

\section{REFERENCES}

Backman, M., Machon, O., Mygland, L., van den Bout, C. J., Zhong, W., Taketo, M. M., et al. (2005). Effects of canonical Wnt signaling on dorso-ventral specification of the mouse telencephalon. Dev. Biol. 279, 155-168.

Boehler, M. D., Wheeler, B. C., and Brewer, G. J. (2007). Added astroglia promote greater synapse density and higher activity in neuronal networks. Neuron Glia Biol. 3, 127-140. doi: 10.1017/S1740925X07000440

Briscoe, J., Sussel, L., Serup, P., Hartigan-O’Connor, D., Jessell, T. M., Rubenstein, J. L., et al. (1999). Homeobox gene Nkx2.2 and specification of neuronal identity by graded Sonic hedgehog signalling. Nature 398, 622-627. doi: 10.1038/19315

Cao, S.-Y., Hu, Y., Chen, C., Yuan, F., Xu, M., Li, Q., et al. (2017). Enhanced derivation of human pluripotent stem cell-derived cortical glutamatergic neurons by a small molecule. Sci. Rep. 7:3282.

Capetian, P., Stanslowsky, N., Bernhardi, E., Grütz, K., Domingo, A., Brüggemann, N., et al. (2018). Altered glutamate response and calcium dynamics in

\section{DATA AVAILABILITY STATEMENT}

The original contributions presented in the study are included in the article/Supplementary Material, further inquiries can be directed to the corresponding author/s.

\section{ETHICS STATEMENT}

The studies involving human participants were reviewed and approved by the Universität zu Lübeck, Ethikkommission, Lübeck, Germany. The participants provided their written informed consent to participate in this study.

\section{AUTHOR CONTRIBUTIONS}

VK, FW, and PC: concept and design, data acquisition, analysis and interpretation, and manuscript writing. MN and NS: data acquisition, analysis, and interpretation (electrophysiology). MP and FS: data acquisition, analysis, and interpretation. BM: data acquisition. PS and CK: concept and design, and interpretation. All authors involved in revising the manuscript for important intellectual content and approved the final version to be published.

\section{FUNDING}

CK and PS received funding from the German Research Foundation (FOR2488) and MP from the Clinician Scientist School Lübeck. This publication was supported by the Open Access Publication Fund of the University of Würzburg.

\section{SUPPLEMENTARY MATERIAL}

The Supplementary Material for this article can be found online at: https://www.frontiersin.org/articles/10.3389/fcell.2021. 716249/full\#supplementary-material

iPSC-derived striatal neurons from XDP patients. Exp. Neurol. 308, 47-58. doi: 10.1016/j.expneurol.2018.06.012

Chambers, S. M., Fasano, C. A., Papapetrou, E. P., Tomishima, M., Sadelain, M., and Studer, L. (2009). Highly efficient neural conversion of human ES and iPS cells by dual inhibition of SMAD signaling. Nat. Biotechnol. 27, 275-280. doi: $10.1038 /$ nbt.1529

Cho, H.-H., Cargnin, F., Kim, Y., Lee, B., Kwon, R.-J., Nam, H., et al. (2014). Isl1 directly controls a cholinergic neuronal identity in the developing forebrain and spinal cord by forming cell type-specific complexes. PLoS Genet. 10:e1004280. doi: 10.1371/journal.pgen.1004280

Coyle, J. T., Price, D. L., and DeLong, M. R. (1983). Alzheimer's disease: a disorder of cortical cholinergic innervation. Science 219, 1184-1190. doi: 10. 1126/science.6338589

Du, T., Xu, Q., Ocbina, P. J., and Anderson, S. A. (2008). NKX2.1 specifies cortical interneuron fate by activating Lhx6. Development 135, 1559-1567. doi: 10.1242/ dev.015123 
Eiraku, M., Watanabe, K., Matsuo-Takasaki, M., Kawada, M., Yonemura, S., Matsumura, M., et al. (2008). Self-organized formation of polarized cortical tissues from ESCs and its active manipulation by extrinsic signals. Cell Stem Cell 3, 519-532. doi: 10.1016/j.stem.2008.09.002

Englund, C., Fink, A., Lau, C., Pham, D., Daza, R. A. M., Bulfone, A., et al. (2005). Pax6, Tbr2, and Tbr1 are expressed sequentially by radial glia, intermediate progenitor cells, and postmitotic neurons in developing neocortex. J. Neurosci. 25, 247-251. doi: 10.1523/JNEUROSCI.2899-04.2005

Ericson, J., Morton, S., Kawakami, A., Roelink, H., and Jessell, T. M. (1996). Two critical periods of sonic hedgehog signaling required for the specification of motor neuron identity. Cell 87, 661-673. doi: 10.1016/s0092-8674(00)81386-0

Fasano, C. A., Chambers, S. M., Lee, G., Tomishima, M. J., and Studer, L. (2010). Efficient derivation of functional floor plate tissue from human embryonic stem cells. Cell Stem Cell 6, 336-347. doi: 10.1016/j.stem.2010.03.001

Fedorova, V., Vanova, T., Elrefae, L., Pospisil, J., Petrasova, M., Kolajova, V., et al. (2019). Differentiation of neural rosettes from human pluripotent stem cells in vitro is sequentially regulated on a molecular level and accomplished by the mechanism reminiscent of secondary neurulation. Stem Cell Res. 40, 101563. doi: 10.1016/j.scr.2019.101563

Gaspard, N., Bouschet, T., Hourez, R., Dimidschstein, J., Naeije, G., van den Ameele, J., et al. (2008). An intrinsic mechanism of corticogenesis from embryonic stem cells. Nature 455, 351-357. doi: 10.1038/nature07287

Gulacsi, A., and Anderson, S. A. (2006). Shh maintains Nkx2.1 in the MGE by a Gli3-independent mechanism. Cereb Cortex 16(Suppl. 1), i89-i95. doi: 10.1093/ cercor/bhk018

Gumy, L. F., Katrukha, E. A., Grigoriev, I., Jaarsma, D., Kapitein, L. C., Akhmanova, A., et al. (2017). MAP2 defines a pre-axonal filtering zone to regulate KIF1versus KIF5-dependent cargo transport in sensory neurons. Neuron 94, 347.e7362.e7. doi: 10.1016/j.neuron.2017.03.046

Harfe, B. D., Scherz, P. J., Nissim, S., Tian, H., McMahon, A. P., and Tabin, C. J. (2004). Evidence for an expansion-based temporal Shh gradient in specifying vertebrate digit identities. Cell 118, 517-528. doi: 10.1016/j.cell.2004.07.024

Huang, S.-M. A., Mishina, Y. M., Liu, S., Cheung, A., Stegmeier, F., Michaud, G. A., et al. (2009). Tankyrase inhibition stabilizes axin and antagonizes Wnt signalling. Nature 461, 614-620. doi: 10.1038/nature08356

Ihnatovych, I., Lew, A., Lazar, E., Sheng, A., Kellermayer, T., and Szigeti, K. (2018). Timing of Wnt inhibition modulates directed differentiation of medial ganglionic eminence progenitors from human pluripotent stem cells. Stem Cells Int. 2018, 3983090. doi: 10.1155/2018/3983090

Kim, D.-S., Ross, P. J., Zaslavsky, K., and Ellis, J. (2014). Optimizing neuronal differentiation from induced pluripotent stem cells to model ASD. Front. Cell Neurosci. 8:109. doi: 10.3389/fncel.2014.00109

Kirkeby, A., Grealish, S., Wolf, D. A., Nelander, J., Wood, J., Lundblad, M., et al. (2012). Generation of regionally specified neural progenitors and functional neurons from human embryonic stem cells under defined conditions. Cell Rep. 1, 703-714. doi: 10.1016/j.celrep.2012.04.009

Levy, L. M., and Hallett, M. (2002). Impaired brain GABA in focal dystonia. Ann. Neurol. 51, 93-101. doi: 10.1002/ana.10073

Li, X.-J., Zhang, X., Johnson, M. A., Wang, Z.-B., Lavaute, T., and Zhang, S.C. (2009). Coordination of sonic hedgehog and Wnt signaling determines ventral and dorsal telencephalic neuron types from human embryonic stem cells. Development 136, 4055-4063. doi: 10.1242/dev.036624

Liu, Y., Liu, H., Sauvey, C., Yao, L., Zarnowska, E. D., and Zhang, S.-C. (2013a). Directed differentiation of forebrain GABA interneurons from human pluripotent stem cells. Nat. Protoc. 8, 1670-1679. doi: 10.1038/nprot.2013.106

Liu, Y., Weick, J. P., Liu, H., Krencik, R., Zhang, X., Ma, L., et al. (2013b). Medial ganglionic eminence-like cells derived from human embryonic stem cells correct learning and memory deficits. Nat. Biotechnol. 31, 440-447. doi: 10.1038/nbt.2565

Ma, L., Hu, B., Liu, Y., Vermilyea, S. C., Liu, H., Gao, L., et al. (2012). Human embryonic stem cell-derived GABA neurons correct locomotion deficits in quinolinic acid-lesioned mice. Cell Stem Cell 10, 455-464. doi: 10.1016/j.stem. 2012.01.021

Marın, O., Anderson, S. A., and Rubenstein, J. L. R. (2000). Origin and molecular specification of striatal interneurons. J. Neurosci. 20, 6063-6076. doi: 10.1523/ JNEUROSCI.20-16-06063.2000

Maroof, A. M., Keros, S., Tyson, J. A., Ying, S.-W., Ganat, Y. M., Merkle, F. T., et al. (2013). Directed differentiation and functional maturation of cortical interneurons from human embryonic stem cells. Cell Stem Cell 12, 559-572. doi: 10.1016/j.stem.2013.04.008

Muñoz, S. S., Engel, M., Balez, R., Do-Ha, D., Cabral-da-Silva, M. C., Hernández, D., et al. (2020). A simple differentiation protocol for generation of induced pluripotent stem cell-derived basal forebrain-like cholinergic neurons for alzheimer's disease and frontotemporal dementia disease modeling. Cells 9, doi: $10.3390 /$ cells 9092018

Muñoz-Sanjuán, I., and Brivanlou, A. H. (2002). Neural induction, the default model and embryonic stem cells. Nat. Rev. Neurosci. 3, 271-280. doi: 10.1038/ nrn786

Nicholas, C. R., Chen, J., Tang, Y., Southwell, D. G., Chalmers, N., Vogt, D., et al. (2013). Functional maturation of hPSC-derived forebrain interneurons requires an extended timeline and mimics human neural development. Cell Stem Cell 12, 573-586. doi: 10.1016/j.stem.2013.04.005

Nicoleau, C., Varela, C., Bonnefond, C., Maury, Y., Bugi, A., Aubry, L., et al. (2013). Embryonic stem cells neural differentiation qualifies the role of $\mathrm{Wnt} / \beta$-Catenin signals in human telencephalic specification and regionalization. Stem Cells 31, 1763-1774. doi: 10.1002/stem.1462

Ochalek, A., Szczesna, K., Petazzi, P., Kobolak, J., and Dinnyes, A. (2016). Generation of cholinergic and dopaminergic interneurons from human pluripotent stem cells as a relevant tool for in vitro modeling of neurological disorders pathology and therapy. Stem Cells Int. 2016:5838934. doi: 10.1155/ 2016/5838934

Oliveira, V. C., Carrara, R. C. V., Simoes, D. L. C., Saggioro, F. P., Carlotti, C. G., Covas, D. T., et al. (2010). Sudan black B treatment reduces autofluorescence and improves resolution of in situ hybridization specific fluorescent signals of brain sections. Histol. Histopathol. 25, 1017-1024. doi: 10.14670/HH-25.1017

Pauly, M. G., Krajka, V., Stengel, F., Seibler, P., Klein, C., and Capetian, P. (2018). Adherent vs. free-floating neural induction by dual SMAD inhibition for neurosphere cultures derived from human induced pluripotent stem cells. Front. Cell Dev. Biol. 6:3. doi: 10.3389/fcell.2018.00003

Petros, T. J., Tyson, J. A., and Anderson, S. A. (2011). Pluripotent stem cells for the study of CNS development. Front. Mol. Neurosci. 4:30. doi: 10.3389/fnmol. 2011.00030

Qi, Y., Zhang, X.-J., Renier, N., Wu, Z., Atkin, T., Sun, Z., et al. (2017). Combined small-molecule inhibition accelerates the derivation of functional cortical neurons from human pluripotent stem cells. Nat. Biotechnol. 35, 154-163. doi: 10.1038/nbt.3777

Qiang, L., Yu, W., Andreadis, A., Luo, M., and Baas, P. W. (2006). Tau protects microtubules in the axon from severing by katanin. J. Neurosci. 26, 3120-3129. doi: 10.1523/JNEUROSCI.5392-05.2006

Schnitzler, A. C., Lopez-Coviella, I., and Blusztajn, J. K. (2008). Differential modulation of nerve growth factor receptor ( $p 75)$ and cholinergic gene expression in purified p75-expressing and non-expressing basal forebrain neurons by BMP9. Brain Res. 1246, 19-28. doi: 10.1016/j.brainres.2008.09.085

Seibler, P., Graziotto, J., Jeong, H., Simunovic, F., Klein, C., and Krainc, D. (2011). Mitochondrial Parkin recruitment is impaired in neurons derived from mutant PINK1 induced pluripotent stem cells. J. Neurosci. 31, 5970-5976. doi: 10.1523/ JNEUROSCI.4441-10.2011

Sinha, S., and Chen, J. K. (2006). Purmorphamine activates the Hedgehog pathway by targeting Smoothened. Nat. Chem. Biol. 2, 29-30. doi: 10.1038/nchembio753

Stanslowsky, N., Haase, A., Martin, U., Naujock, M., Leffler, A., Dengler, R., et al. (2014). Functional differentiation of midbrain neurons from human cord blood-derived induced pluripotent stem cells. Stem Cell Res. Ther. 5:35. doi: $10.1186 /$ scrt423

Stengel, F., Vulinovic, F., Meier, B., Grütz, K., Klein, C., and Capetian, P. (2020). Impaired differentiation of human induced neural stem cells by TOR1A overexpression. Mol. Biol. Rep. 47, 3993-4001. doi: 10.1007/s11033-020-05390$\mathrm{x}$

Sterneckert, J. L., Reinhardt, P., and Schöler, H. R. (2014). Investigating human disease using stem cell models. Nat. Rev. Genet. 15, 625-639. doi: 10.1038/ $\operatorname{nrg} 3764$

Sun, A. X., Yuan, Q., Tan, S., Xiao, Y., Wang, D., Khoo, A. T. T., et al. (2016). Direct Induction and functional maturation of forebrain GABAergic neurons from human pluripotent stem cells. Cell Rep. 16, 1942-1953. doi: 10.1016/j.celrep. 2016.07.035

Sussel, L., Marin, O., Kimura, S., and Rubenstein, J. L. (1999). Loss of Nkx2.1 homeobox gene function results in a ventral to dorsal molecular respecification 
within the basal telencephalon: evidence for a transformation of the pallidum into the striatum. Development 126, 3359-3370.

Takahashi, K., Tanabe, K., Ohnuki, M., Narita, M., Ichisaka, T., Tomoda, K., et al. (2007). Induction of pluripotent stem cells from adult human fibroblasts by defined factors. Cell 131, 861-872. doi: 10.1016/j.cell.2007.11.019

Tomishima, M. (2008). StemBook: Conditioning Pluripotent Stem Cell Media with Mouse Embryonic Fibroblasts (MEF-CM). Cambridge, MA: Harvard Stem Cell Institute.

van den Ameele, J., Tiberi, L., Vanderhaeghen, P., and Espuny-Camacho, I. (2014). Thinking out of the dish: what to learn about cortical development using pluripotent stem cells. Trends Neurosci. 37, 334-342. doi: 10.1016/j.tins.2014. 03.005

Wang, S., Zou, C., Fu, L., Wang, B., An, J., Song, G., et al. (2015). Autologous iPSCderived dopamine neuron transplantation in a nonhuman primate Parkinson's disease model. Cell Discov. 1:15012. doi: 10.1038/celldisc.2015.12

Waskom, M. (2021). seaborn: statistical data visualization. JOSS 6:3021. doi: 10. 21105/joss. 03021

Watanabe, K., Kamiya, D., Nishiyama, A., Katayama, T., Nozaki, S., Kawasaki, H., et al. (2005). Directed differentiation of telencephalic precursors from embryonic stem cells. Nat. Neurosci. 8, 288-296. doi: 10.1038/nn 1402

Watanabe, K., Ueno, M., Kamiya, D., Nishiyama, A., Matsumura, M., Wataya, T., et al. (2007). A ROCK inhibitor permits survival of dissociated human embryonic stem cells. Nat. Biotechnol. 25, 681-686. doi: 10.1038/nbt1310
Whitehouse, P. J., Price, D. L., Struble, R. G., Clark, A. W., Coyle, J. T., and Delon, M. R. (1982). Alzheimer's disease and senile dementia: loss of neurons in the basal forebrain. Science 215, 1237-1239. doi: 10.1126/science.7058341

Xu, Q., Wonders, C. P., and Anderson, S. A. (2005). Sonic hedgehog maintains the identity of cortical interneuron progenitors in the ventral telencephalon. Development 132, 4987-4998. doi: 10.1242/dev.02090

Conflict of Interest: The authors declare that the research was conducted in the absence of any commercial or financial relationships that could be construed as a potential conflict of interest.

Publisher's Note: All claims expressed in this article are solely those of the authors and do not necessarily represent those of their affiliated organizations, or those of the publisher, the editors and the reviewers. Any product that may be evaluated in this article, or claim that may be made by its manufacturer, is not guaranteed or endorsed by the publisher.

Copyright $(2021$ Krajka, Naujock, Pauly, Stengel, Meier, Stanslowsky, Klein, Seibler, Wegner and Capetian. This is an open-access article distributed under the terms of the Creative Commons Attribution License (CC BY). The use, distribution or reproduction in other forums is permitted, provided the original author(s) and the copyright owner(s) are credited and that the original publication in this journal is cited, in accordance with accepted academic practice. No use, distribution or reproduction is permitted which does not comply with these terms. 